DOI: http://dx.doi.org/10.18764/2178-2229.v26n4p186-199

\title{
O PROFESSOR DA EDUCAÇÃO PROFISSIONAL ENQUANTO SUJEITO DA PRÁXIS REVOLUCIONÁRIA
}

THE PROFESSIONAL EDUCATION TEACHER AND THE REVOLUTIONARY PRAXIS EL PROFESOR DE EDUCACIÓN PROFESIONAL Y LA PRAXIS REVOLUCIONARIA

\author{
João Kaio Cavalcante de Morais ${ }^{1}$ \\ Ana Lúcia Sarmento Henrique ${ }^{2}$ \\ llane Ferreira Cavalcante ${ }^{3}$
}

\section{RESUMO}

O presente artigo tem como objetivo discutir aspectos do trabalho docente na educação profissional (EP) tendo como base a práxis revolucionária. Para isso, recorremos aos estudos de Konder (1992), Marx e Engels (1998) e Vázquez (2011). Logo, o referencial teórico e metodológico está imbricado no materialismohistórico dialético. Partimos do pressuposto de que a EP é uma modalidade de ensino que está inserida no contexto de disputas antagônicas. Por essa razão, defendemos uma EP que busque evidenciar o trabalho como princípio educativo, a partir de um currículo integrado com vistas à formação humana integral dos sujeitos. Nesse sentido, o professor que atua na EP carece de construir uma consciência de classe, tendo em vista que a práxis revolucionária busca a transformação da sociedade atual. Para além disso, urge a necessidade de aproximações mutualísticas entre os componentes curriculares da formação profissional para com aqueles da formação geral. Compreendemos que a revolução acontece nos mais variados espaços, com as mais variadas pessoas e estilos de pensamento e ação. Todos esses pequenos movimentos podem corroborar no sentido de buscar uma transformação de realidades coletivas, sobretudo daqueles mais carentes. O professor, nesse caso, é um sujeito fundamental - mas não único - nesse processo.

Palavras-chave: Educação Profissional. Práxis Revolucionária. Formação de Professores.

\begin{abstract}
The article aims to analyze the work of teachers in Vocational Education (PE) following the revolutionary praxis. We consulted the research of Konder (1992), Marx and Engels (1998) and Vázquez (2011). Our method is historical dialectical materialism. We defend a Vocational Education with work as an educational principle, integrated curriculum and integral human formation. The teacher needs to have a class consciousness because revolutionary praxis wants to transform today's society. We believe in the relationship between general education subjects and technical subjects. We know that the revolution happens in many places, with many different people and different styles of thinking the world. The teacher is fundamental in this process, but not the only one.
\end{abstract}

Keywords: Professional Education. Revolutionary Praxis. Training Teachers.

\section{RESUMEN}

Este artículo tiene como objetivo discutir aspectos del trabajo docente en Educacion Profesional (EP) basado en la praxis revolucionaria. Para ello, recurrimos a los estudios de Konder (1992), Marx y Engels (1998) y Vázquez (2011). Así, el marco teórico y metodológico está incrustado en el materialismo histórico dialéctico. Asumimos que la EP es una modalidad de enseñanza que se inserta en el contexto de disputas

\footnotetext{
1 Instituto Federal de Educação, Ciência e Tecnologia do Rio Grande do Norte (IFRN). Natal/RN - Brasil. ORCID: 0000-0001-6984-3629. E-mail: kaio-ca-valcante@hotmail.com

2 Instituto Federal de Educação, Ciência e Tecnologia do Rio Grande do Norte (IFRN). Natal/RN - Brasil. ORCID: 0000-0002-1536-7986. E-mail: ana.henrique@ifrn.edu.br

3 Instituto Federal de Educação, Ciência e Tecnologia do Rio Grande do Norte (IFRN). Natal/RN - Brasil. ORCID: 0000-0002-1783-9879. E-mail: ilane.cavalcanti@ifrn.edu.br
}

Artigo recebido em outubro de 2019. Aprovado em novembro de 2019. 
antagónicas. Por esta razón, defendemos una EP que busca destacar el trabajo como un principio educativo, basado en el currículo escolar integrado con miras a la formación humana integral de las personas. Los profesores que trabaja en EP necesita construir una conciencia de clase, ya que la praxis revolucionaria busca la transformación de la sociedad actual. Además, existe la necesidad de aproximaciones mutualistas entre los componentes curriculares de la formación profesional y los de la educación general. Sabemos que la revolución ocurre en los espacios más variados, con las más variadas personas y estilos de pensamiento y acción. Todos estos pequeños movimientos pueden corroborar la búsqueda de una transformación de las realidades colectivas, especialmente las más necesitadas. El profesor es un tema fundamental en este proceso, pero no el único.

Palabras clave: Educacion Profesional. Praxis revolucionaria. Formación de Profesores

\section{INTRODUÇÃO}

Assim como os demais trabalhadores, o professor está inserido no contexto do modo de produção capitalista. Ele vende sua força de trabalho para o dono do capital - em uma escola privada, por exemplo -, ou para o Estado, nas diferentes redes de ensino - federal, estadual ou municipal. Esses professores são assalariados, sem propriedade dos meios de produção, possuindo parcial controle do processo de trabalho e flexibilizado nas suas formas de contratação (MIRANDA, 2015).

Sendo assim, o docente pode ser considerado um trabalhador mediante a lógica do capital, por exercer uma atividade regulada por um contrato de trabalho, uma das características fundamentais do modo de produção capitalista. Moura (2014) ainda lembra que, apesar de o trabalho docente ser produtivo, ou seja, ocorre em meio às relações capitalistas de compra e venda da força de trabalho, esse trabalho não é material, pois não se pode separar o trabalhador (o professor) do produto do seu trabalho (a aprendizagem dos estudantes), é como um sistema de retroalimentação.

De acordo com Coelho (2012), apesar de ser um trabalhador, a atuação docente apresenta suas especificidades, tendo em vista que o objeto do seu trabalho é o próprio ser humano com capacidade de resistir ou de participar do fazer cotidiano do docente. Essas interações acontecem em um ambiente específico, ou seja, em uma escola ou instituição de ensino, delimitada em um contexto histórico, social, político, econômico e cultural.

Em nosso texto, discutiremos aspectos do trabalho docente na Educação Profissional (EP) a partir dos fundamentos da práxis revolucionária. A práxis aqui evidenciada tem um caráter de unidade teoria e prática numa perspectiva de revolução e transformação da realidade material, conceito construído por Vázquez (2011), a partir da abordagem marxiana e marxista de Karl Marx, Friedrich Engels e Vladimir Ulyanov (Lenin).

Para basilar nosso estudo, recorremos aos estudos de Konder (1992), Kuenzer (2009), Vázquez (2011), Ciavatta (2012) e Moura (2014), dentre outros. Além disso, utilizamos alguns dispositivos de leis, o que caracteriza essa pesquisa como bibliográfica e documental. Para alcançar tal intento, utilizaremos o método histórico-dialético, o que se coaduna com os autores utilizados neste texto e a própria intencionalidade da práxis revolucionária.

Cumpre destacar que a EP é uma modalidade de ensino garantida pela Lei de Diretrizes e Bases da Educação Nacional (LDBEN, 9.394/96), cujo Art. 39 dispõe que "a educação profissional e tecnológica, no cumprimento dos objetivos da educação nacional, integra-se aos diferentes níveis e modalidades de educação e às dimensões do trabalho, da ciência e da tecnologia". Esse artigo normatiza e confere legalidade à $E P$, além de apresentar o trabalho, a ciência e a tecnologia como dimensões formativas. Reforçando essa garantia, o Art. 36-A estabelece relações da EP com o Ensino Médio (EM) ao evidenciar que "sem prejuízo do disposto na Seção IV deste Capítulo, o ensino médio, atendida a formação geral do educando, poderá prepará-lo para o exercício de profissões técnicas". Essa preparação pode acontecer de "forma articulada com 
o ensino médio ou subsequente, em cursos destinados a quem já tenha concluído o ensino médio", assim como estabelece o Art. 36-B (BRASIL, 1996, n.p.).

Apesar de assegurada enquanto modalidade de ensino atrelada ao EM, observamos que por decorrência da Lei $n^{0} 13.415 / 17$, de 16 de fevereiro de 2017, promulgada pelo então presidente Michel Temer, a EP está sendo reduzida a um itinerário formativo nessa etapa da educação escolar. O dispositivo altera os artigos relacionados ao EM na última LDBEN. Após reformulação, o artigo esclarece, no Art.36, que o "currículo do ensino médio deve ser composto pela Base Nacional Comum Curricular (BNCC) e por itinerários formativos", dentre eles, a "formação técnica e profissional" (BRASIL, 2017).

Nessa lógica, o adolescente e/ou jovem terá uma carga horária destinada aos conhecimentos comuns e um aprofundamento no itinerário formativo de sua escolha, podendo acontecer em outro espaço formativo, o que, segundo Moura e Lima Filho (2019), ataca a concepção de EM como etapa final da Educação Básica (EB), afrontando a atual LDBEN e os princípios constitucionais do direito subjetivo à educação e da universalização da EB.

A Lei $n^{0} 13.415 / 17$ conforma-se como uma contrarreforma educacional (RAMOS; FRIGOTTO, 2017), a partir do currículo, esquecendo a realidade educacional dos sistemas de ensino. Além disso, reduz a EP a um itinerário formativo, o que acarreta mais um momento histórico de distanciamento entre teoria e prática, pensar e fazer, entre ricos e pobres. Aprofunda-se, portanto, a ideia de uma EP centrada no desenvolvimento de competências para atender ao mercado de trabalho em detrimento de um projeto de escola que forma o sujeito em sua integralidade.

Contrapondo-se a uma formação fragmentada, centrada no desenvolvimento de competências e habilidades para atender ao mercado de trabalho, Frigotto (1985), Ciavatta (2000), Kuenzer (1997), Manfredi (2002), Moll (2010), Ramos (2011) e Oliveira (2012), foram fundamentais no sentido de problematizar essa formação. A defesa desses autores tem como base as concepções de homem, trabalho, ciência e tecnologia encontradas inicialmente nos estudos de Marx e Engels (MARX; ENGELS, 1998).

Marx (2019, p.29) defendia, no contexto do século XIX, um "ensino público e gratuito para todas as crianças. Abolição do trabalho das crianças nas fábricas em sua forma atual ${ }^{4}$. Unificação do ensino com a produção material". Essa educação se daria a partir do desenvolvimento mental, físico e tecnológico. O intuito era superar o modo de produção capitalista a partir do domínio da ciência (desenvolvimento mental) e da tecnologia.

Nesse sentido, fica exposto, apenas no fragmento citado, a defesa de Marx (2019) por uma educação pública e gratuita, a partir da unificação entre trabalho manual e trabalho intelectual. No contexto brasileiro do século XXI, acreditamos que uma das possibilidades de concretude dessa formação está na articulação e integração da EB à EP, tendo como fundamento o trabalho como princípio educativo, a partir de um currículo integrado com vistas à formação humana integral.

Pensar e materializar o trabalho docente, no atual contexto brasileiro, e a partir da práxis, é ressaltar seu caráter de resistência, revolução, transformação e emancipação, algo extremamente necessário no atual cenário neoliberal e neoconservador que adentra na economia, sociedade, política e, sobretudo, no sistema de ensino do país. A escola com perspectivas neoliberal forma força de trabalho para engendrar o modo de produção. A práxis revolucionária, no entanto, não desvincula teoria e prática, forma e sentido, pensamento e ação, ciência e trabalho. Logo, se contrapõe a essa perspectiva.

\footnotetext{
${ }_{4}^{4}$ De acordo com Cestari e Melo (2019), O trabalho infantil, durante muitos séculos, foi considerado uma prática rotineira e natural. Antes da Revolução Industrial, crianças também trabalhavam, mas não eram exploradas. Elas ajudavam na economia da própria família, sem se preocupar com tempo e disciplina. Com o processo de industrialização, a criança tornou-se parte integrante da economia capitalista. Segundo os autores, no século XIX, em pleno apogeu do modo de produção capitalista, as crianças, a partir de seis anos de idade, eram chamadas de aprendizes, sendo obrigadas a trabalhar por até catorze horas por dia, durante toda a semana. Ao escrever sobre a educação escolar, Marx estava situado nesse contexto.
} 


\section{TEORIA E PRÁTICA COMO UNIDADE: A PRÁXIS REVOLUCIONÁRIA}

A palavra práxis provém do grego antigo, sendo comumente relacionada à ação que se realizava no âmbito das relações pessoais e de contemplação. Era uma ação intersubjetiva, moral, entre os cidadãos (KONDER, 1992). Vázquez (2011) diz que cabia aos homens gregos e romanos contemplativos o direito à práxis. A atividade meramente prática era realizada pelos escravos e considerada indigna para os homens livres e contemplativos, ou seja, para os sujeitos da práxis. Percebemos, portanto, um desprezo pelas atividades materiais e uma contemplação da atividade intelectual desde os gregos e romanos.

Nesse sentido, percebemos uma negação da unidade teoria e prática material produtiva emergindo entre os gregos e romanos. Vázquez (2011, p.41) pontua que "Platão teve, inclusive, a consciência de que a teoria deve ser prática, isto é, de que o pensamento e a ação devem-se manter em unidade, e o lugar desta unidade é a política". Aristóteles, por sua vez, admite, assim como Platão, a legitimidade da práxis política, mas sempre com um nível inferior à vida teórica. Para Aristóteles, a práxis é o fundamento da teoria. Tanto para Platão como para Aristóteles o homem só se realiza verdadeiramente na vida teórica. Portanto, há, nesses filósofos, a negação da unidade entre teoria e prática material produtiva. De acordo com Konder (1992, p. 97), esses filósofos encaravam a práxis como a atividade ética e política, distinta da atividade produtiva.

A consciência filosófica da práxis, na sociedade escravista antiga, corresponde aos interesses da classe dominante e é, por isso, uma concepção negativa das relações entre teoria e prática produtiva. Vázquez (2011, p. 45) pontua que "a consciência filosófica da práxis sofre uma mudança radical no Renascimento". Segundo o autor, naquele momento, o homem deixa de ser um simples animal teórico para ser também sujeito ativo, construtor e criador do mundo. Reivindica-se a dignidade humana não só na contemplação, como também na ação; o homem, ente de razão, é também ente de vontade. A razão permite-lhe compreender a natureza; sua vontade permite dominar e modificar a natureza de acordo com os interesses econômicos da burguesia e do nascente modo capitalista de produção.

O futuro da burguesia, bem como o seu poder, estava ligado à transformação prático-material do mundo e ao progresso da ciência e da técnica, condicionados, por sua vez, por tal transformação. O homem, nesse contexto, continuou alterando a natureza com o intuito de produzir sua existência. Para isso, o polo da contemplação precisou ser direcionado para o polo da razão. Com a Revolução Industrial, observamos cada vez mais o valor do trabalho humano e da técnica, mesmo que isso não tenha ocasionado uma valorização do trabalhador. A ciência e a tecnologia converteram-se em força material e questão central para o progresso da sociedade capitalista.

A experiência e a prática apresentavam, a partir desse movimento, uma nova conotação: elas buscavam transformar a natureza. Apesar disso, essa prática ainda estava condicionada à teoria. Segundo Vázquez (2011, p. 50), "para Bacon e para Descartes, a potência do homem está na atividade teórica. O que muda é sua concepção sobre ela: empirista, no primeiro e racionalista, no segundo". Logo, para o homem que produz ciência no apogeu do capitalismo, a prática é preterida em relação à teoria.

Compreendemos que, com o processo de expansão e consolidação do modo de produção capitalista, a atividade prática e racional elevou-se ao sentido de modificação da natureza para atender aos interesses dos burgueses. Apesar disso, essa atividade prática era vista de forma hierarquizada, ou seja, a prática estava submetida à teoria. O homem se fazia na teoria, mas precisava da prática para conseguir atender as suas necessidades e as do capitalismo.

A partir dessa análise, podemos inferir que havia um movimento de síntese entre teoria e prática, superando a concepção de práxis que havia até entre os gregos e nas sociedades feudais, em que era negligenciada totalmente entre os homens livres. 
Apesar disso, Konder (1992, p.192) chama atenção para uma impossibilidade dessa síntese acontecer. Para o autor, a ideologia dominante implicava a "convicção de que a práxis, como exercício consciente e responsável da cidadania, só podia ser privilégio de uma elite bem preparada, integrada por homens empreendedores, proprietários de bens asseguradores.".

A partir dessa análise, é possível perceber o sentido produtivo e classista conferido à práxis na sociedade capitalista. Para Konder (1992) e Vázquez (2011), a práxis produtiva emergiu para atender aos interesses imediatos do modo de produção capitalista e da ciência, porém não deveria ser realizada por todos. Em outras palavras, enquanto uma classe social dominava o conhecimento científico, outra colocava em prática a partir do trabalho manual.

É no apogeu do capitalismo que emergiram os estudos de Marx e Engels acerca da práxis. De acordo com Konder (1992, p.103), "foi em Manuscritos EconômicosFilosóficos, de 1844, que Marx começou a desenvolver uma concepção original de práxis. Foi então que ele começou a determinar diferenças importantes entre diversos tipos de atividades.". Vázquez (2011) pontua que Marx e Engels são fundamentais para a compreensão da práxis, mas ressalta que Lenin estabeleceu a unidade teoria e prática, entre socialismo e ciência e, desse modo, colocou em seu verdadeiro lugar a práxis revolucionária.

O cerne da práxis - em sentido marxiano - está contido nos estudos desenvolvidos por Marx e Engels. Para além de uma análise acerca do modo de produção capitalista, eles desenvolveram um construto teórico e científico fundamental para a compreensão a respeito da práxis e da dialética. Esses autores produziram uma ampla crítica ao materialismo pragmático e ao idealismo alemão de sua época. Para eles, a realidade material não pode ser desarticulada dos condicionantes históricos, bem como os homens não são seres prioritariamente do pensamento, como propusera Georg Hegel.

Vázquez (2011, p. 111) comenta que a relação entre teoria e prática é, para Marx, teórica e prática. É "prática, na medida em que a teoria, como guia da ação, molda a atividade do homem, particularmente a atividade revolucionária; teórica, na medida em que esta relação é consciente". Logo, o homem é um sujeito teórico e prático ao mesmo tempo que busca modificar e transformar uma determinada realidade. Se essa realidade deve ser mudada, a filosofia não pode ser um instrumento teórico de conservação ou justificação da realidade, mas de sua transformação.

Marx e Engels (1998), portanto, estabeleceram uma profunda ruptura no pensamento filosófico que partia da separação entre contemplação e transformação da realidade. Para eles, não bastava pensar sobre a realidade nem apenas entender como ela se produz, era necessário modificá-la. Por isso, argumentavam que os filósofos buscavam apenas compreender o mundo, mas a questão é transformá-lo. Essa transformação está vinculada aos diferentes segmentos da existência humana, ou seja, social, cultural, político e econômico.

Marx e Engels são fundamentais na compreensão do conceito de práxis, entretanto, ela é desenvolvida em sua plenitude a partir de Lenin, como pontua Vázquez (2011). Lenin viveu no contexto do século XX - após, portanto, os estudos de Marx e Engels permeado por duas discussões acerca das abordagens marxistas. Um grupo defendia um marxismo científico, enquanto outros acreditavam que o pensamento de Marx e Engels era necessariamente prático e revolucionário.

Como sujeito da práxis, Lenin unificou novamente o seu sentido, tendo em vista que ressaltava homens e mulheres como indivíduos do pensamento e da ação, da teoria e da prática, mas sem negligenciar o caráter revolucionário. A práxis revolucionária de Lenin é tão importante que não conseguimos desarticular os seus escritos de suas ações políticas e revolucionárias no período da Revolução Russa, no século passado. 
A partir desse cenário, que ressalta a necessidade de pensar e fazer uma práxis revolucionária, Vázquez (2011, p. 398) desenvolve uma síntese dialética, ao situar que

\begin{abstract}
Entendemos a práxis como atividade material humana transformadora do mundo e do próprio homem. Essa atividade real, objetiva, é, ao mesmo tempo, ideal, subjetiva e consciente. Por isso, insistimos na unidade entre teoria e prática, unidade que também implica certa distinção e relativa autonomia. A práxis não tem para nós um âmbito tão amplo que possa, inclusive, englobar a atividade teórica em si, nem tão limitado que se reduza a uma atividade apenas material.
\end{abstract}

Konder (1992, p. 115) reforça essa abordagem assegurando que "a práxis é uma atividade concreta pela qual os sujeitos humanos se afirmam no mundo, modificando a realidade objetiva". Segundo o autor, a práxis é a "ação que, para se aprofundar de maneira mais consequente, precisa da reflexão, do autoquestionamento, da teoria; e é a teoria que remete à ação, que enfrenta o desafio de verificar seus acertos e desacertos, cotejando-os com a prática".

Compreendemos, portanto, que a práxis se apresenta como uma atividade material, transformadora e dirigida a determinado fim. Tem, pois, um traço semântico teleológico. Distante dela, fica a atividade teórica que não se materializa, na medida em que é atividade espiritual pura. Entretanto, não há práxis como atividade puramente material, isto é, sem a produção de conhecimentos, que caracteriza a atividade meramente teórica. (VÁZQUEZ, 2011).

Em nosso entendimento, a partir dos estudos de Konder (1992) e Vázquez (2011), a práxis apresenta duas premissas básicas: a indissociabilidade entre teoria e prática e uma finalidade, ou seja, a necessidade de transformar uma realidade. Portanto, é uma atividade essencialmente teleológica. Essa práxis da prática se retroalimenta em uma teoria que tem objetivos claros de transformação das mais variadas dimensões da vida dos homens e das mulheres. O conhecimento, nessa perspectiva, portanto, não é decorrente de uma abstração ou contemplação, como acreditavam os gregos antigos, ele é resultado da necessidade material dos seres humanos de transformarem a si e à natureza. Nessa lógica, não há uma hierarquização entre teoria e prática, tendo em vista que elas estão fundidas em uma única dimensão.

Para além dessa perspectiva, na práxis, existe intrinsecamente um sentido revolucionário, que advém de seu traço semântico teleológico. É uma condição teórica e prática que aspira, busca melhorar radicalmente uma sociedade. Toda práxis tem um caráter futurístico, ou seja, trabalha a favor de um melhor por vir humano. (VÁZQUEZ, 2011).

Acreditamos que a práxis revolucionária, compreendida como instrumento de unidade teoria e prática com o objetivo de transformar a realidade posta, está vinculada, de forma visceral, ao aspecto educativo. Para Sousa Júnior ${ }^{5}$, trata-se de uma práxis político-educativa que se configura como atividade material, prática imprescindível para qualquer projeto de transformação social. Nesse sentido, as instituições de ensino são espaços possíveis de materialização da práxis. No próximo tópico, discorreremos especificamente a respeito do trabalho docente na EP, a partir de uma abordagem da práxis revolucionária.

\title{
3 DISCUSSÕES ACERCA DAS POSSIBILIDADES DE UMA PRÁXIS REVOLUCIONÁRIA DOCENTE NA EDUCAÇÃO PROFISSIONAL
}

No tópico anterior, problematizamos alguns pressupostos do conceito de práxis a partir das abordagens marxistas de Vázquez (2011) e Konder (1992) 6 . Neste momento, pretendemos dialogar a respeito da EP enquanto espaço viável para a construção da

\footnotetext{
O conceito foi expresso por Justino de Sousa Júnior, na conferência intitulada Regressão Social (acima de todos) e resistência da classe trabalhadora (acima de tudo). A palestra ocorreu na abertura do V Colóquio Nacional e II Colóquio Internacional: a produção do conhecimento em educação profissional, em Natal, Rio Grande do Norte, no ano de 2019.

6 A edição de Konder (1992) é mais antiga, porém o estudo de Vázquez (2011) foi desenvolvido primeiro.
}

Cad. Pesq., São Luís, v. 26, n. 4, p. 186-199, out./dez. 2019. 
práxis revolucionária no Brasil. Para alcançar tal finalidade, consultamos os estudos de Kuenzer (2009), Ciavatta (2012), Moura (2014), dentre outros.

Acreditamos que a EP é o local propício para materialização da proposta da práxis revolucionária, tendo em vista que essa modalidade de educação está assegurada pela LDBEN, 9.394/96, podendo ser integrada ou articulada à EB (BRASIL, 1996). Logo, é uma realidade material garantida por lei e desenvolvida no Brasil, nas redes privada, estadual e, sobretudo, na Rede Federal de Educação Profissional e Tecnológica. Além disso, a EP articulada/integrada à EB também vem ganhando espaço nas redes estaduais de ensino, inclusive em regiões historicamente mais frágeis economicamente, como por exemplo, o Norte e o Nordeste do Brasil.

Para além dessas instituições públicas, a EP também é desenvolvida em instituições privadas e filantrópicas, o que configura uma heterogeneidade de sentido e das formas dessa modalidade educacional no país. Apesar disso, a nossa defesa está centrada em uma escola pública, gratuita, laica e de qualidade socialmente referenciada, ou seja, a qualidade da educação deve ter como centro de atenção os trabalhadores e as trabalhadoras e não o mercado e as necessidades do capitalismo.

Essa escola da classe trabalhadora encontra seu alicerce nas abordagens marxianas e marxistas de homem, trabalho, ciência, sociedade, tecnologia. Discutimos, neste texto, a formação humana baseada na dialética marxiana e marxista. Marx e Engels (1998) reconheciam o homem como um ser natural, o qual se desenvolve nesse domínio imposto e único que é a natureza. Dentro dessa perspectiva, significa aceitar o ser humano como alguém que pertence à natureza e que, por isso, encontra-se submetido ao estatuto de sua dependência, tal como qualquer outro ser vivo.

Essa abordagem não reduz a existência humana a qualquer ordem fisiológica substancial da qual o seu comportamento seria apenas uma manifestação. Pelo contrário, tal definição busca indicar a dependência do homem em relação à natureza que lhe é exterior, aos objetos que existem fora de si e lhe são independentes, como uma relação primordial, originária, a partir da qual o dever humano se elabora, e não algum termo no qual tudo estaria contido como predicados em sua substância. (MARX, ENGELS, 1998).

Nesse sentido, o trabalho como princípio educativo vincula-se, então, à própria forma de ser dos seres humanos. Estes se constituem enquanto parte da natureza dependendo dela para reproduzir a vida. Se essa é uma condição fundante, socializar o princípio do trabalho como produtor de valores de uso para manter e reproduzir a vida é crucial e educativo. (FRIGOTTO; CIAVATTA; RAMOS, 2015).

A partir dos estudos de Ramos (2015), situamos que além do trabalho, a ciência, a tecnologia e a cultura fazem parte da formação humana integral. De acordo com a autora, a ciência é a reunião dos conhecimentos produzidos pela humanidade em processos mediados pelo trabalho, pela ação humana, que se tornam legitimados socialmente como conhecimentos válidos porque explicam a realidade e possibilitam a intervenção sobre ela. Portanto, trabalho e ciência formam uma unidade, uma vez que o ser humano foi produzindo conhecimentos à medida que interagia com a natureza para suprir suas próprias necessidades.

Um outro elemento constituinte da formação humana integral, e que está relacionada aos dois conceitos discutidos no parágrafo anterior, é a tecnologia. Compreendemos tecnologia como a mediação entre ciência (apreensão e desvelamento do real) e produção (intervenção no real). De acordo com Moura (2007), é necessário apreender a tecnologia como construção social complexa integrada às relações sociais de produção.

Portanto, mais que força material da produção, a tecnologia, cada vez mais indissociável das práticas cotidianas, em seus vários campos/diversidades/tempos e espaços, assume uma dimensão sociocultural, uma centralidade geral e não específica na sociabilidade humana. A tecnologia passou a ter um lugar de centralidade em quase 
todas as práticas sociais, em particular, no processo educativo e de pesquisa. Assim, o trabalho como categoria central de produção de saber, bem como a ciência e a tecnologia são indissociáveis. (LIMA FILHO, 2005).

Além disso, o outro constituinte da formação humana de caráter integral é a cultura que vem acompanhada de valores e normas que orientam os grupos sociais. Ramos (2015, p. 4) diz que os "grupos sociais compartilham valores éticos, morais, simbólicos que organizam a sua ação e a produção estética, artística etc.".

Logo, compreendemos que o homem é um ser social, que se utiliza da ação planejada do trabalho para transformar a natureza com o intuito de suprir suas necessidades. Ao estabelecer essa relação com a natureza, o homem produz conhecimento, o qual é repassado para as gerações futuras por meio da cultura. Então, em seu sentido ontológico, o homem deveria ser formado em espaço escolar para que pudesse assumir uma postura que lhe proporcionasse o entendimento dessa dinâmica sobre o conhecimento. (MORAIS, 2017).

Aliado a isso, compreendemos que a ideia de formação humana integral sugere superar o ser humano dividido historicamente pela divisão social do trabalho. Ciavatta (2012) lembra que se trata de ir além da formação para o trabalho operacional, simplificado, escoimado dos conhecimentos que estão na sua gênese científico-tecnológica e na sua apropriação histórico-social. Ao contrário disso, busca-se garantir ao estudante o direito a uma formação completa para a leitura do mundo e para a atuação como cidadão pertencente a um país, integrado dignamente à sociedade política. Formação que, nesse sentido, supõe a compreensão das relações sociais subjacentes a todos os fenômenos.

Tal formação deveria apresentar aspectos de criticidade, de reflexões em torno do atual modo de produção hegemônico. É relevante, na formação humana, a compreensão não apenas dos fenômenos naturais físicos, químicos e biológicos, por exemplo, mas também da história da sociedade e das contradições do modo de produção capitalista. Isso, se trabalhado de forma articulada/integrada, pode contribuir no sentido de formar os homens a partir de uma perspectiva crítica, transformadora e emancipatória. (MORAIS, 2017).

Entendemos, a partir dessa discussão teórica, que a formação humana integral abrange as mais variadas dimensões da vida humana, levando em consideração os elementos que a constituem: o trabalho, a ciência, a tecnologia e a cultura. Além do caráter formativo humano de crescimento intelectual, essa formação também deveria desenvolver nos sujeitos um olhar crítico sobre as contradições do modo de produção vigente. Logo, deve-se formar os sujeitos numa perspectiva crítico-transformadora. (MORAIS, 2017).

Sinalizamos que é preciso uma discussão acerca da materialização desses pressupostos ou, ao menos, dos fundamentos pedagógicos e didáticos para que isso aconteça. Ao recorrer à literatura, percebemos que o caminho mais coerente com o pensamento do trabalho como princípio educativo, numa perspectiva de formação humana integral, seria, de maneira mais generalizada, o currículo integrado.

$\mathrm{Na}$ concretude desse currículo, deveria ser levado em consideração o tipo de sociedade em que se vive, a relevância do trabalho em seu sentido ontológico como princípio educativo e a EP como espaço adequado para a materialização dessa proposta, dada a dualidade educacional brasileira e a aproximação necessária entre adolescentes, jovens e adultos para com as discussões envolvendo o mundo do trabalho. Ao professor caberia a função de participar da sua construção, possibilitando sua ressignificação a partir das experiências adquiridas. (MORAIS, 2017).

Ramos (2012) aponta três pressupostos que deveriam fundamentar a organização curricular numa perspectiva integrada: o primeiro deles é a concepção de homem como ser histórico-social que age sobre a natureza - discutido ao longo deste tópico 
-. O segundo remete à realidade concreta. Disso decorre outra perspectiva, de ordem epistemológica, que consiste em compreender o conhecimento como uma produção do pensamento pelo qual se apreende e se representam as relações que constituem e estruturam a realidade objetiva.

Dessa forma, entendemos que a proposta de currículo aqui tratada abarca muito mais que apenas um conjunto de diretrizes para o contexto das práticas escolares. Defendemos uma abordagem ético-político-formativa, imbuída da concepção de luta de classes, na qual trabalho, ciência, tecnologia e cultura são indissociáveis da formação crítica, emancipatória e transformadora. (MORAIS, 2017).

Constituir um currículo nessa perspectiva é compreender que isso exige um método, que parte do concreto, do empírico e, mediante a determinação mais precisa através da análise, chega-se a relações gerais que são determinações mais precisas da realidade concreta. (RAMOS, 2012). Ou seja, o currículo, mediante essa proposta, deve ser pensando a partir de uma situação concreta, real, empírica.

Dessa forma, o currículo integrado deve organizar o conhecimento e desenvolver os processos de ensino e aprendizagem de forma que os conceitos científicos sejam apreendidos como sistema de relações de uma totalidade concreta que se pretende explicar/compreender. Busca-se, portanto, um distanciamento da fragmentação do pensamento empirista, racionalista, mecanicista, funcionalista e positivista, desenvolvido no decorrer dos séculos XIX e XX.

O currículo integrado, elaborado sobre essas bases, não hierarquiza os conhecimentos nem os respectivos campos das ciências, mas os problematiza em suas historicidades, relações e contradições. (RAMOS, 2011). Algo que possibilita aos estudantes formarem uma noção do todo e não de um fragmento, como vem sendo construído nos processos de ensino e aprendizagem nas instituições de ensino deste país.

A própria concepção de currículo integrado já se institui de forma revolucionária. Manfredi (2002) lembra que a EP sempre esteve submetida aos interesses das classes dominantes no Brasil. Os filhos da elite eram formados para adquirir os conhecimentos historicamente construídos, enquanto os filhos dos desvalidos e/ou trabalhadores, recebiam preparos básicos para assumir ofícios instrumentais. Ao evidenciar um currículo que supere essa dualidade, estamos corroborando para transformações individuais e coletivas, bem como para unidade entre teoria e prática.

Uma formação, na perspectiva do currículo integrado deve apresentar aspectos de criticidade, de reflexões em torno do atual modo de produção hegemônico, bem como de sua superação. Está circunscrito na abordagem marxiana a necessidade de transformar o mundo mediante a realidade prática, ou seja, real, mediante a práxis. Homens e mulheres devem ser formados no sentido de compreender o movimento da sociedade capitalista com o intuito de transformá-la e superá-la. Essa transformação deve ser igualitária em sentido social, político, econômico e das subjetividades, ou seja, da individualidade de cada um.

O professor, nesse contexto, desempenha um papel fundamental, tendo em vista que é o principal responsável pelos processos de ensino nas instituições escolares do país. Para trabalhar nessa perspectiva, o docente necessita, primeiramente, se reconhecer enquanto sujeito da classe trabalhadora. Suas ações e práticas devem, em primeira e última instância, apresentarem relações mais concretas com os objetivos dos trabalhadores, tendo em vista que, como já discutido anteriormente, o professor é um trabalhador. Logo, o fazer revolucionário docente não se restringe apenas aos espaços escolares, tendo em vista que, nos movimentos sociais, o professor também pode fazer revolução, colocando sua práxis na rua.

Cumpre salientar que o professor é um profissional que está condicionado a realidade material posta. Em outras palavras, ele está inserido em uma instituição de 
ensino, situada em um contexto único. O seu trabalho é consequência do processo de formação inicial e continuada, bem como de políticas públicas educacionais centradas na valorização da profissão docente. Um professor que atua em uma instituição de ensino recebendo salários baixos, sem formação continuada e com uma estrutura escolar precária, terá mais dificuldades de materializar uma práxis revolucionária, entretanto, isso não deve ser motivo para esmorecer. O seu reconhecimento como parte da classe trabalhadora pode contribuir nesse aspecto, uma vez que os docentes são fundamentais no processo de desenvolvimento da educação, ciência, tecnologia e cultura do país, logo ainda apresentam apreço da sociedade civil organizada.

Para além das questões de reconhecimento enquanto sujeitos da classe trabalhadora, o professor desempenha suas funções em uma instituição de ensino, com alunos, sejam eles crianças, adolescentes, jovens ou adultos. Nesse contexto dialético, o professor ensina e ao mesmo tempo aprende. Apesar disso, sua principal função é construir conhecimento com os estudantes, ou seja, possibilitar que os alunos aprendam. Essa aprendizagem apresenta aspectos teóricos/cognitivos e práticos que não podem ser quantificados, mesmo existindo inúmeras avaliações internas e externas. A partir disso, evidenciamos que o trabalho docente é imaterial, pois o produto - a aprendizagem do aluno - não pode ser quantificado ou materializado como objeto. Logo, o professor carece de realizar reflexões em torno do seu trabalho, recorrendo ao seu repertório de saberes para efetivar os processos de ensino e aprendizagem. É na ação-reflexão-ação que o docente se faz docente, assim como estabelece Freire (1997).

Levando em consideração a natureza e as características do trabalho docente, compreendemos que uma dimensão importante está atrelada ao posicionamento desse profissional frente ao seu componente curricular de ensino. Sem adentrar nas especificidades das áreas do conhecimento, gostaríamos de chamar a atenção para a necessidade de o docente que atua na EP desenvolver uma práxis que integre seu(s) componente(s) com as demais, sejam elas da base comum ou da formação profissional?

O professor que está em constante processo de formação consegue realizar esse movimento de forma mais satisfatória. A formação inicial possibilita o acesso a um repertório de conhecimentos inerentes ao seu componente curricular, no caso dos professores licenciados, mas não o acesso a todas as possibilidades para efetivar os processos de ensino e aprendizagem. É no cotidiano que o professor problematiza seus saberes, construindo-os e reconstruindo-os, em um movimento permanente e dialético que não se desvincula, em nenhum momento, da teoria.

Muitos dos professores acreditam que a prática pedagógica não apresenta relação com a teoria estudada nos cursos de formação inicial e continuada. Na visão simplista desses docentes, o que se faz nas escolas de EP está distante das abordagens teóricas estudadas no decorrer dos cursos. Logo, acreditamos que o professor necessita compreender, após um período de formação profissional, que o seu fazer é realizado em relação mutualística com a teoria. O trabalho docente é, portanto, teórico-prático. Por decorrência do positivismo científico de meados do século XIX, instalou-se, nas instituições escolares, uma ideia de hierarquização entre teoria e prática. Primeiro ensina-se o teórico, depois o prático, ou vice-versa. Na práxis revolucionária, não existe essa distinção, ao mesmo tempo que é teórico, é prático. Ao mesmo tempo que é prático, é teórico.

Sabendo disso, os professores podem planejar, executar e replanejar suas aulas levando em consideração que a ordem teoria e depois prática não deve ser fundamento. Os conhecimentos, sistematizados e organizados em conteúdos de ensino apresentam características e necessidades diversas, cabendo aos professores e alunos decidirem a ordem de sua construção. O professor, portanto, é um profissional que se faz junto aos sujeitos do seu trabalho, os discentes.

\footnotetext{
Comumente, um professor pode atuar em mais de um componente curricular na EP. Por exemplo, o professor bacharel formado em Engenharia Elétrica, que atua em um curso técnico de Eletrotécnica, pode desempenhar seu fazer nas disciplinas de Eletromagnetismo, Circuitos Combinacionais, Instalações Prediais, dentre outras.
} 
Para além de uma preocupação com os processos de ensino e aprendizagem em sua disciplina, o docente da práxis carece de estabelecer relações simbióticas com os componentes curriculares da formação técnica e profissional dos estudantes. Em um curso técnico de nível médio em Eletrotécnica, por exemplo, os professores das disciplinas de Artes, Física, Língua Portuguesa, Matemática e Língua Inglesa podem corroborar com as disciplinas específicas do curso, buscando uma práxis integradora e integrativa com vistas à formação para o trabalho, sem cunho instrumentalista. Em sentido oposto, os professores da área específica do curso - Eletrotécnica - podem fortalecer, aprofundar e/ou ressignificar os conceitos da práxis construídos outrora em disciplinas basilares como a Física.

O planejamento é fundamental para alcançar tal intuito. As instituições de ensino precisam construir verdadeiros ecossistemas de planejamento, no qual os professores saibam exatamente o que ensinar, quando ensinar e como estabelecer relações com outros componentes curriculares, com isso, será possível trabalhar em consonância com o currículo integrado. É preciso fortalecer as trocas de saberes acerca da contribuição das disciplinas para a formação básica e profissional dos estudantes. Ao mesmo tempo que ensinam, os docentes da formação básica e da formação profissional aprendem uns com os outros. Essa rede ecológica de saberes permite uma construção integrada do conhecimento em ambiente escolar, tenha esse saber uma perspectiva científica, cultural, artística ou profissional.

Para além da abordagem pedagógica e didática da práxis docente, chamamos a atenção para uma necessidade de o professor contribuir para a transformação da realidade posta, o que engloba as contradições internas do modo de produção capitalista e sua interferência na cultura, na ciência, na tecnologia etc. Por essa característica, o docente precisa construir uma visão crítica a respeito do mundo e das relações sociais. Como um profissional do ensino poderá corroborar com uma visão transformadora da realidade por parte dos alunos se ele não acredita nisso? As práticas precisam conectarse com os discursos.

No imaginário do senso comum, inclusive de alguns colegas professores, a transformação da realidade acontece a partir do momento em que homens e mulheres confrontam o sistema pela força física, ou seja, em processos revolucionários armados. É bem sabido que, no decorrer da história, essa tenha sido uma das principais estratégias, entretanto, ela não é a única.

O processo de capilaridade do capital no decorrer das últimas décadas tem possibilitado concessões para a classe trabalhadora-que também passa por um processo de capilaridade - atuar em diferentes frentes. A necessidade básica de formação para o trabalhador, decorrente do regime de acumulação flexível, possibilitou que organismos internacionais ligados ao capital injetassem dinheiro em países estratégicos a partir da década de 1990, dentre eles, o Brasil.

A educação escolar sempre atendeu aos interesses dos poderosos, não seria diferente atualmente. O mercado de trabalho exige um profissional habilitado, qualificado e até aceita que este transforme sua realidade através dos estudos. Contraditoriamente, não é de interesse da educação neoliberal e neoconservadora possibilitar a transformação da realidade social, tendo em vista que isso implica uma inversão da relação entre as duas principais classes sociais, ou seja, trabalhadores e proprietários do meio de produção.

É nesse cenário dialético que o professor e os alunos da EP se situam como sujeitos da práxis revolucionária. Não podemos esperar que as escolas apresentem uma proposta revolucionária de educação pronta, tendo em vista que elas estão inseridas na lógica do capital e do Estado capitalista, sobretudo quando estas formam os trabalhadores para se inserirem na lógica do capital. Essa condição não limita hoje a escola, de uma forma geral, e os professores, de uma forma específica, a desenvolverem 
práticas e ações com vistas à transformação das realidades individuais e coletiva dos sujeitos que ali estão.

Em inúmeras ações simples do cotidiano podemos localizar o fazer da práxis revolucionária. Ao possibilitar que o estudante tenha acesso ao conhecimento historicamente construído pela humanidade, o professor faz revolução. Além disso, ao preparar o aluno para o ingresso no ensino superior, ele revoluciona. Ao docente que persiste e não desiste de evidenciar as contradições desumanas que levam atualmente 3,8 bilhões de pessoas à pobreza no mundo, ele revoluciona. Ao mobilizar outros docentes e a equipe escolar a reivindicar melhoria na qualidade da merenda escolar e nos serviços da escola, ele revoluciona. A partir do momento em que ele se reconhece enquanto parte da classe trabalhadora, ele revoluciona.

A revolução acontece nos mais variados espaços, com as mais variadas pessoas e estilos de pensamento e ação. Todos esses pequenos movimentos podem corroborar no sentido de buscar uma transformação de realidades coletivas, sobretudo daqueles mais carentes. O professor, nesse caso, é um sujeito fundamental - mas não único nesse processo.

\section{CONSIDERAÇÕES FINAIS}

No decorrer deste texto, refletimos em torno da práxis revolucionária no contexto do trabalho docente na EP. Primeiro, situamos para o leitor nossa defesa em torno de uma EP desenvolvida tendo como fundamento o trabalho como princípio educativo, a partir de um currículo integrado com vistas à formação humana integral. Atualmente, a conjuntura mais apropriada para que isso aconteça é na integração/articulação dessa modalidade de ensino com a EB, a partir do currículo integrado.

Para além disso, discutimos, brevemente, o sentido da práxis a partir dos estudos de Konder (1992) e Vázquez (2011). Vimos que, historicamente, a prática sempre foi considerada inferir à teoria. Na visão marxiana e marxista, teoria e prática não estão desvinculadas, tendo em vista que elas formam uma unidade. A prática se alimenta na teoria, assim como a teoria se alimenta na prática. Existe uma fusão teórico-prática. Não existe, portanto, uma distância entre pensar e fazer. Essa unidade teoria e prática precisa ter uma finalidade, ou seja, a transformação da realidade material e a busca por uma nova realidade. Por esse motivo, a práxis revolucionária é educativa, teleológica e atemporal.

Feito esse movimento, apresentamos alguns pressupostos basilares do trabalho docente para o projeto de EP que defendemos, dentre eles: a formação humana integral, o trabalho como princípio educativo e o currículo integrado. Esses elementos já balizam o trabalho docente para a práxis revolucionária, tendo em vista que busca formar os sujeitos em sua integralidade, tendo o trabalho como elemento fundante. Posteriormente, sinalizamos algumas necessidades para atuação do docente em consonância com a práxis revolucionária.

Com isso, consideramos fundamental compreender o papel pedagógico e didático do professor na integração teoria e prática com vistas à práxis. Temos consciência de que esse estudo teórico apresenta apenas os elementos potencializadores para discussões empíricas, extremamente necessárias. A cada realidade dada, cabe uma profunda reflexão. Logo, sugerimos que pesquisas centradas nesta temática sejam desenvolvidas em instituições de ensino, sejam elas federais, estaduais, municipais ou privadas, desde que atendam aos filhos da classe trabalhadora.

\section{REFERÊNCIAS}

BRASIL. Lei $n^{\circ}$ 9.394/96, de 20 de dezembro de 1996. Estabelece as diretrizes e bases da educação nacional. Brasília, DF, Disponível em: <http://www.planalto.gov.br/ccivil_03/leis/ 19394.htm>. Acesso em: 02 jul. 2019. 
BRASIL. Decreto n 13.415, de 16 de fevereiro de 2017. Altera as Leis ns 9.394, de 20 de dezembro de 1996, que estabelece as diretrizes e bases da educação nacional, e 11.494, de 20 de junho 2007, que regulamenta o Fundo de Manutenção e Desenvolvimento da Educação Básica e de Valorização dos Profissionais da Educação, a Consolidação das Leis do Trabalho - CLT, aprovada pelo Decreto-Lei $n^{0} 5.452$, de $1^{\circ}$ de maio de 1943, e o Decreto-Lei ${ }^{\circ} 236$, de 28 de fevereiro de 1967; revoga a Lei $n^{0}$ 11.161, de 5 de agosto de 2005; e institui a Política de Fomento à Implementação de Escolas de Ensino Médio em Tempo Integral.. . Brasília, DF, Disponível em: <https://www2.camara.leg.br/legin/fed/lei/2017/lei-13415-16-fevereiro-2017784336-publicacaooriginal-152003-pl.html>. Acesso em: 27 set. 2019.

CESTARI, Marisa Aparecida; MELLO, Ricardo Marques de. Trabalho infantil: um comparativo entre a revolução industrial e os dias atuais. Disponível em: <http://www.diaadiaeducacao. pr.gov.br/portals/cadernospde/pdebusca/producoes_pde/2016/2016_artigo_hist_unesparcampomourao_marisaaparecidacestari.pdf>. Acesso em: 04 nov. 2019.

CIAVATTA, Maria. A educação profissional do cidadão produtivo à luz de uma análise de contexto. Proposta, v. 29, n.86, p. 76-89, 2000.

CIAVATTA, Maria. A formação integrada: a escolar e o trabalho como lugares de memória e de identidade. In: FRIGOTTO, Gaudêncio; CIAVATTA, Maria; RAMOS, Marise (Org.). Ensino Médio Integrado: Concepção e Contradições. 3. ed. São Paulo: Cortez, 2012. p. 83-107.

COELHO, José Silvestre. 0 trabalho docente na escola integrada. 2012. 212 f. Dissertação (Mestrado em Educação) - Curso de Educação, Universidade Federal de Minas Gerais, Belo Horizonte, 2012.

FREIRE, Paulo. Política e educação: ensaios. São Paulo: Cortez, 1997.

FRIGOTTO, Gaudêncio. Trabalho como princípio educativo: por uma superação das ambigüidades. Boletim Técnico do SENAC, Rio de Janeiro, v. 11, n. 3, p. 175-182, set /dez. 1985.

FRIGOTTO, Gaudêncio; CIAVATTA, Maria; RAMOS, Marise. 0 trabalho como princípio educativo no projeto de educação integral de trabalhadores: Excertos. Disponível em: <http://redeescoladegoverno.fdrh.rs.gov.br/upload/1392215839_O TRABALHO COMO PRINCÍPIO EDUCATIVO NO PROJETO.pdf>. Acesso em: 17 out. 2015.

KONDER, Leandro. 0 futuro da filosofia da práxis: o pensamento de Marx no século XXI. $2^{\circ}$ ed. Rio de Janeiro: Paz e Terra, 1992.

KUENZER, Acácia. Ensino médio e profissional: as políticas do estado neoliberal. 4. ed. São Paulo: Cortez, 2009.

LIMA FILHO, Domingos Leite. A universidade tecnológica e sua relação com o ensino médio e a educação superior: discutindo a identidade e o futuro dos CEFETs. IN: Perspectiva Revista do Centro de Ciências da Educação da UFSC, Florianópolis, v. 23, n. 2, p. 349- 380, 2005.

MANFREDI, Silvia Maria. Educação profissional no Brasil. São Paulo: Cortez, 2002.

MARX, Karl; ENGELS, Friedrich. A ideologia alemã. São Paulo: Martins Fontes, 1998.

MARX, Karl; ENGELS, Friedrich. Instruções para os Delegados do Conselho Geral Provisório. As Diferentes Questões. Disponível em: <https://www.marxists.org/portugues/ marx/1866/08/instrucoes.htm>. Acesso em: 21 jul. 2019. 
MIRANDA, Kênia. A natureza do trabalho docente na acumulação flexível. Disponível em: <http://www.unicamp.br/cemarx/ANAIS IV COLOQUIO/comunicações/GT5/gt5m3c3.pdf>. Acesso em: 28 out. 2015.

MOLL, Jaqueline (Org.). Educação profissional e tecnológica no Brasil contemporâneo: desafios, tensões e possibilidades. Porto Alegre: Armed, 2010.

MOURA, Dante Henrique. A função social da rede federal de educação profissional e tecnológica na educação brasileira. Tecnologia \& Desenvolvimento Sustentável, v. 1, p. 3- 23, 2007.

MOURA, Dante Henrique. Trabalho e formação docente na educação profissional. Curitiba: IFPR, 2014.

MOURA, Dante Henrique; LIMA FILHO, Domingos Leite. A reforma do ensino médio: regressão dos direitos sociais. Revista Retratos da Escola, Brasília, v. 20, n. 11, p.109-129, set. 2019.

MORAIS, João Kaio Cavalcante de. Os saberes docentes necessários ao trabalho do professor de Biologia no Ensino Médio Integrado. 2017. 130 f. Dissertação (Mestrado) Curso de Educação Profissional, Instituto Federal de Educação, Ciência e Tecnologia do Rio Grande do Norte, Natal, 2017.

OLIVEIRA, Ramon de. (Org.) Jovens, ensino médio e educação profissional: políticas públicas em debate. $1^{\circ} \mathrm{ed}$. Campinas: 2012.

RAMOS, Marise Noqueira. O currículo para o ensino médio em suas diferentes modalidades: concepções, propostas e problemas. Educação e Sociedade, Campinas, v. 32, n. 116, p. 771- 788, jul. 2011.

RAMOS, Marise Nogueira. Possibilidades e desafios na organização do currículo integrado. In: FRIGOTTO, Gaudêncio; CIAVATTA, Maria; RAMOS, Marise (Org.). Ensino Médio Integrado: concepção e contradições. 3. ed. São Paulo: Cortez, 2012. p. 107-129.

RAMOS, Marise Nogueira. Concepção do ensino médio integrado. Disponível em: <http:// www.iiep.org.br/curriculo_integrado.pdf>. Acesso em: 08 out. 2015.

RAMOS, Marise Nogueira; FRIGOTTO, Gaudêncio. "RESISTIR É PRECISO, FAZER NÃO É PRECISO": AS CONTRARREFORMAS DO ENSINO MÉDIO NO BRASIL. Cadernos de Pesquisa em Educação, [s.I.], v. 22, n. 46, p.26-47, 31 dez. 2017.

VÁZQUEZ, Adolfo Sánchez. Filosofia da práxis. $2^{\circ}$ ed. São Paulo: Expressão popular, 2011. 